\title{
Analysis using multiple free space optic channel with amplification to mitigate haze attenuation
}

\author{
A.A.Anis, C.B.M.Rashidi, S.A.Aljunid \\ Advance Communication Engineering, Centre of Excellence, School of Computer and Communication Engineering, \\ Universiti Malaysia Perlis, Malaysia
}

\begin{tabular}{l} 
Article Info \\
\hline Article history: \\
Received Sep 25, 2018 \\
Revised Nov 26, 2018 \\
Accepted Jan 28, 2019 \\
\hline
\end{tabular}

Keywords:

Atmospheric attenuation Bit error rate (BER)

Diameter aperture

Free space optics (FSO)

Visibility

\begin{abstract}
Weather severity has unfavorable effect on FSO transmission performance. The impact could result in poor quality of transmission and communication failure. This paper presents the analysis using multiple free space optic channels with amplification to mitigate haze attenuation. The visibility is progressively reduced due to the attenuation effects, causing the bit error rate to increase. Three designs of FSO system are proposed in this research as they are simulated and analysed thoroughly using Optisys software. The achieved result shows improved performance for Design 3, as the minimum BER achieved is $10-127$ when the power received is $-26 \mathrm{dBm}$, and maximum Q-factor of 23.6 at the aperture diameter of $40 \mathrm{~cm}$. It is proved to improve the system efficiently in low visibility condition compared to Design 1 and Design 2. It clearly has shown the superior capabilities of Design 3 to intercept and mitigate the atmospheric attenuation in haze condition as the power loss during transmission also reduced significantly.
\end{abstract}

Copyright () 2019 Institute of Advanced Engineering and Science. All rights reserved.

\section{Corresponding Author:}

\author{
A.A.Anis, \\ Advance Communication Engineering, Centre of Excellence, \\ School of Computer and Communication Engineering, \\ Universiti Malaysia Perlis, (UniMAP), Pauh Putra, 02600, Arau, Malaysia. \\ Email: anis_afina@ymail.com
}

\section{INTRODUCTION}

Free Space Optic (FSO) is a communication system which delivers the light via the air as a medium. Normally, the system has several main components. The first one is the light source which is modulated at high bit rate. The second one is the telescope which is used to direct the light to other transponders (an active tracking system for beam alignment to maximize throughput of the communication system), and the third one is the receiver amplifier which functions to increase and optimize received signals. The usual light sources used are laser and LEDs [1-2]. Figure 1 shows the block diagram of a basic FSO system and Figure 2 shows the block diagram of a transmitter.

Nowadays, FSO has become a conventional technology, which plays an important role in the networking applications. It is due to the extreme changes in the communication network infrastructure. In the near future, free space optics is going to be a great method towards the high speed networks [4] because of the continuance of the increasing use of internet in the past decade. Before the implementation of FSO system, optical fiber or wireless LAN technologies are widely used. Optical fiber communication system transmits signals faster and more secure. Nevertheless, it is costly and time-consuming to make the cable facilities. Although wireless LAN is a common mobile communication service, it has a weak point in security [5] even if any encryption is applied such as WPA/WPA2-PSK. 


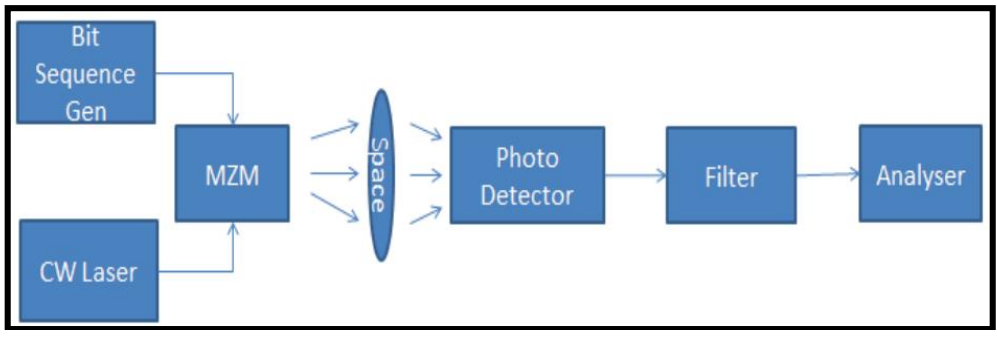

Figure 1. Block diagram of FSO system [3]

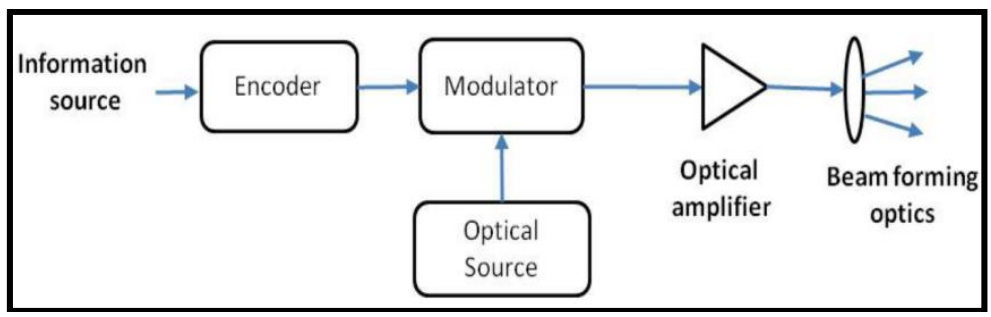

Figure 2. Block diagram of a transmitter [6]

FSO is a substitute wireless communication method, which transmits a collimated laser beam from a transmitter to a receiver through lenses and mirrors [7-8]. FSO is easier to set up compared to optical fiber cables as FSO laser beam is transmitted between two collimator lenses of the transmitter and receiver without using the transmission cables. FSO also has larger bandwidth and higher security than the radio wave. FSO is an optical technology that offers a high-speed last-mile solution, unlimited bandwidth and free licensing of frequency. However, this technology needs a clear line of sight [9] between the source and the destination. So, the transmitter and receiver are usually mounted at the roof top of buildings.

The main rawback of this technology is the impact of weather conditions [10-12] such as fog, haze, rain and scintillation on the efficiency of the FSO system condition especially in long distance transmission. A number of studies have reported that the range of FSO links operating in the temperate and tropical regions to be limited by fog and heavy rainfall respectively. However, the literature on the effect of haze attenuation on FSO link is relatively limited, especially in Malaysia. The effects of haze on FSOsystem can be determined by estimating the scattering coefficient. The atmospheric attenuation can be calculated based on the scattering coefficient of small particles like haze, fog and smoke as the signal transmission becomes more dependent on the wavelength.

The molecule compounds in the air are uneven. They keep changing because of the weather conditions. In FSO, losses of signal can happen due to atmospheric effects [13] which can be categorized into two namely:

1. Atmospheric attenuation

\subsection{Absorption}

1.2 Scattering

2. Atmospheric turbulence

2.1 Laser beam deformation

The atmosphere is considered as a stimulating dynamical channel for electromagnetic wave transmission as the scattering, absorption and turbulence are the primary mechanisms of signal attenuation and distortion [14-15]. The scattering process happens when light waves bump into particles or molecules of dissimilar sizes and shapes. However, absorption is a quantum effect that is defined by wavelength-based atmospheric windows. Turbulences are triggered by the hot air pockets that diffract the optical signals. There are two classes of atmospheric constituents which are the particles of maximum $1 \mu \mathrm{m}$ in radius and the particles consisting of hydrometers. For the first class, the particles are suspended in the air because of their small sizes and very lightweight. They form a continuum called Aerosol and the Scattering by aerosol is called haze [16]. Aerosol particles are smog, fine soil particles, cosmic dusts, clouds, fog and others.

In the other class, the particles could be in liquid state, cloud, mist, fog, rain, ocean spray, or solid state, hail or snow. Usually, these particles are larger than $1 \mu \mathrm{m}$ in radius and exist over a shorter period of time than the smaller particles. 


\section{SYSTEM DESIGN AND METHODOLOGY}

There are three main components of an FSO system. They are the transmitter, the FSO channel, and the receiver. The transmitter includes Pseudo-Random Bit Generator, NRZ Pulse Generator, CW Laser, and Mach-Zehnder Modulator. The APD photo detector and Low Pass Gaussian Filter are used at the receiver end. BER analyser and optical power meter is used to picture the simulation value.

Previously, a study was made on the effect of atmospheric attenuation during hazy days for FSO communication in point to point connection and found that the wavelength of $1550 \mathrm{~nm}$ is better than $850 \mathrm{~nm}$ in performance parameters of scattering coefficient and atmospheric attenuation [17].

However, FSO system using multiple transceivers has a number of advantages such as large link distance and better bit error performance. Thus, FSO system using spatial diversity technique and three ways of optical amplifications were proposed and investigated [18]. It concluded that System 1 (pre-amplification system) shows the best BER performance and provides maximum range of $338 \mathrm{~km}$ within acceptable received power compared to System 2 (post-amplification system) and System 3 (pre-post amplification system). System 1 has an optical transmitter linked to a fork as the first fork yields multiple beam and this fork is connected to another set of forks which also yields multiples laser beam. These beams are combined by a power combiner. An optical amplifier is installed before output is directed to the FSO channel.

This research paper is proposed to study and design the FSO system as it is developed using the software called OptiSystem. The designs of FSO system developed as shown in Figure 3 and are briefly discussed in the sub topic IV below. The designs developed are named Design 1, Design 2, and Design 3. Each on the design differs from each other and has distinctive characteristics to study the impact of haze on them. From the simulation using the same software, evaluations were made based on the achieved results.

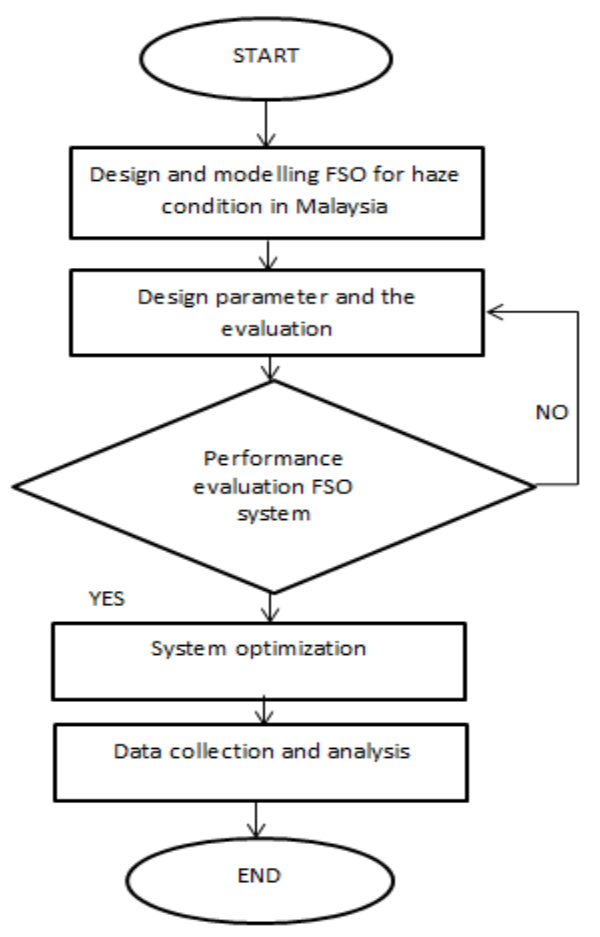

Figure 3. Flow chart of the research methodology

\section{PERFORMANCE ANALYSIS OF HAZE}

Scattering by aerosol is termed as haze. Aerosol is a tiny and very light-weighted particle, suspended in the air. Commonly, the suspending gas is air. This term defines an aero-solution, clouds of microscopic particles in the air. The size of aerosol particles ranges from 0.1 to $1 \mu \mathrm{m}$. Another definition of Aerosol is the extremely-fine liquid droplets or solid particles that stay suspended in the air as fog or smoke. Haze particles have tiny salt crystals, dusts or products of combustion. They also have diameter ranges of $0.02 \mu \mathrm{m}$ to $2 \mu \mathrm{m}$. The diameter is larger than the incident wavelength of the FSO laser beam. So, Mie scattering occurs during the hazy days. The effect of Rayleigh scattering can be ignored as it is too small [19]. 
The maximum distance which prominent objects, such as mounting, buildings or towers can be seen with naked eyes is termed as visibility. The FSO transmission during hazy days is really poor as haze is one of the main limitations of the FSO system. There are several ways to mitigate this issue. The first one is by deploying the system with shorter link or by increasing the transmittance power. The second way is by employing longer wavelengths. A $1550 \mathrm{~nm}$ laser would sufficiently provide the power required to face the signal attenuation [17].

The scattering coefficient is used to measure the effects of haze to the FSO systems as it relies on the visibility conditions. When the concentrations and sizes of the particles are higher compared to average visibility, the condition is called low visibility. This causes more scattering and attenuations. The atmospheric attenuation can be calculated based on scattering coefficient. For small particles like haze, fog and smoke, the transmission relies on the wavelength. Table 1 presents some values of atmospheric attenuation due to scattering based on haze visibility. The pattern shows that optical signals with greater wavelength are able to penetrate low visibility condition.

Table 1. Variation in Atmospheric Attenuation Due Scattering based on Visibility

\begin{tabular}{ccc}
\hline $\begin{array}{c}\text { Visibility, S (line of sight) } \\
(\mathrm{km})\end{array}$ & $\begin{array}{c}\text { Wavelength } 800 \mathrm{~nm} \\
(\mathrm{~dB} / \mathrm{km})\end{array}$ & $\begin{array}{c}\text { Wavelength } 2500 \mathrm{~nm} \\
(\mathrm{~dB} / \mathrm{km})\end{array}$ \\
\hline 0.5 & 32.5 & 30.8 \\
0.7 & 23 & 21 \\
0.9 & 18 & 16 \\
1.1 & 14.5 & 12.5 \\
1.3 & 12 & 10 \\
1.5 & 10 & 8.33 \\
\hline
\end{tabular}

When the different of length between the two optical paths differs, the energy passes through minima and maxima. The condition can be expressed as 1 . The visibility $\mathrm{V}$ is defined by:

$$
V=\frac{I_{\text {Max }}-I_{\text {Min }}}{I_{\text {Max }}+I_{\text {Min }}}
$$

where: $\quad I_{\text {Max }}=$ maximum estimated light level

$I_{\text {Min }}=$ minimum estimated light level

The visibility is affected by three factors which are the degree of coherence of the source, the length difference between the paths, and the location of the detector with respect to the source. The coherence between the beams received by the detector is also influenced by the crossed media. Coherent sources can be employed for indirect sight links.

The effectiveness and availability of FSO systems is reduced by low visibility conditions. The condition can be happening randomly, during a specific time period within a year or at specific times of the day. Low visibility means the concentration and the size of the particles are higher, compared to an average visibility. Thus, scattering and attenuation may be more in low visibility conditions.

The visibility conditions can be categorized as low visibility $(\mathrm{V}<6 \mathrm{~km})$, average visibility $(6 \mathrm{~km}<\mathrm{V}<50 \mathrm{~km})$ and high visibility $(\mathrm{V}>50 \mathrm{~km})$. Mie scattering is dominated in hazy days. The scattering coefficient can be expressed as a function of the visibility and wavelength. The scattering coefficient in hazy days can be determined using the expression in 2 .

$$
\beta=\frac{3.91}{V}\left(\frac{\lambda}{550 n m}\right)
$$

where: $\mathrm{V}=$ visibility in kilometers

$1=$ wavelength in nanometers

$\mathrm{q}=$ the size distribution of the scattering particles

$\mathrm{q}=\left\{\begin{array}{l}1.6 \text { for high visibility }(\mathrm{V}>50 \mathrm{~km}) \\ 1.3 \text { for average visibility }(6 \mathrm{~km}<\mathrm{V}<50 \mathrm{~km}) \\ 0.585 \mathrm{~V}^{1 / 3} \text { for low visibility }(\mathrm{V}<6 \mathrm{~km})\end{array}\right.$ 


\section{FSO SYSTEM MODEL}

Figure 4 depicts the block diagram of the Design 1. For Design 1, a continuous wave (CW) Laser is used as the optical source at the transmitter side. Pseudo-Random Bit Sequence Generator and non-return-tozero (NRZ) Pulse Generator are installed in the circuit to provide modulating electrical signal input to the Mach-Zehnder Modulator. The modulated signal is transmitted through both FSO channels. Each FSO channel is connected to a PIN photodiode. PIN photodiode functioned as a photo detector which received and converted the optical signal to an electrical signal. A low pass Bessel filter is used to filter out unwanted frequency. The received signal is analyzed using an Eye Diagram analyzer. The $3 \mathrm{R}$ regenerator is used to regenerate an electrical signal of the original bit sequence, and the modulated electrical signal in the transmitter as to be used for Eye Diagram analysis. This design is made as a reference design to propose the other FSO system designs in improving the link performance in haze conditions.

Figure 5 shows the block diagram for design 2. At the transmitter side, Design 2 is installed with only a single transmitter with Pseudo-Random Bit Sequence Generator, NRZ Pulse Generator, and MachZenhder Modulator. However, there are two CW lasers installed in this design. This modification has made Design 2 to be better than Design 1 in term of link performance, proven from the simulation analysis. As compared to Design 1 which only has one transmitter and dual FSO channels, Design 2 used two-beam link which provided a better system performance as more optical signals were loss when the optical channel was increased. Studies made in 2006 found that there was a significant improvement in BER performance as significant signal-to-noise-ratio gains have been obtained by using a four-beam link over a single-beam link with the same power [20-21].

Ultimately, it is supposed to the best improve performance, compared to the other two designs. Modifications are made on Design 1 and Design 2 to accomplish Design 3 in Figure 6. A study [22-24] found that there were FSO system improvements as average spectral efficiency increased when using multiple inputs, multiple output (MIMO) system, compared to single input, single output (SISO) system. From the study, it has been improved that MIMO system was able to minimize the BER efficiently. Compared to Design 1 and Design 2, Design 3 is installed with five channels of FSO channel which simultaneously transmitted the signals from the transmitter side to the receiver side. Since the numbers of optical channel are increased to five, the probability of the optical signal to be scattered during transmission was also increased. So, an optical amplifier was purposely installed at the end of both optical channels at both transmitter and receiver sides. Its purpose is to amplify the optical signal power, to strengthen the signal during transmission via the optical channel, and to maintain the optical power at a high level at the transmitter side. So, the atmospheric attenuation effects on the link are reduced and the system performance is improved in hazy conditions.

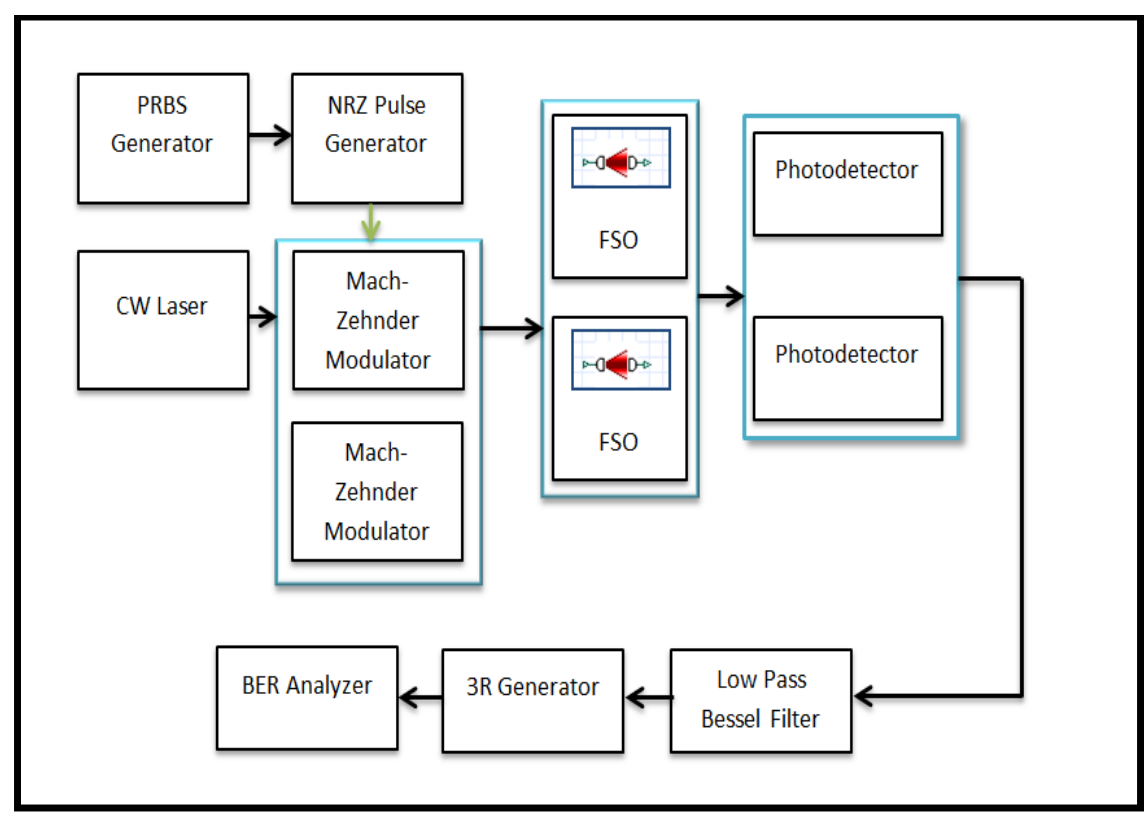

Figure 4. Block diagram for design 1 


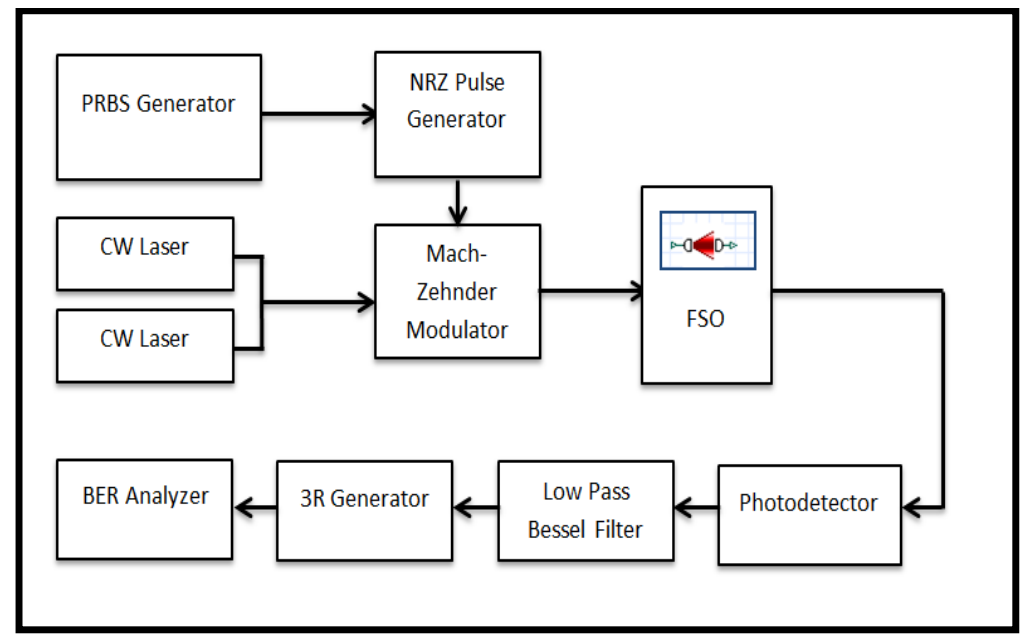

Figure 5. Block diagram for design 2

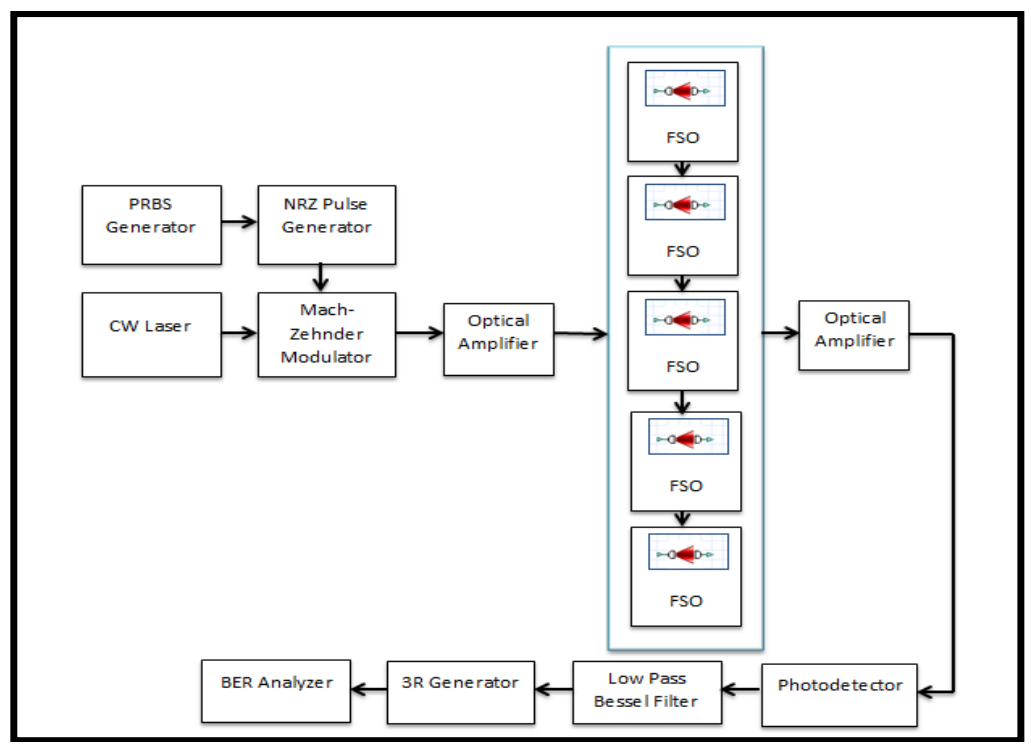

Figure 6. Block diagram for design 3

In this design, two separate links are transmitted which one of them is amplified using an RF signal before being modulated by Mach-Zehnder Modulator. There are several advantages of an RF amplifier which are better selectivity, better sensitivity, and improved signal to noise ratio. Another function is to increase the output power to a higher level. At the receiver end, an optical power meter is installed at each end to monitor the received power for each link. The results of system performance for Design 1 in term of BER are used as benchmarks to study the improved performance as other designs are proposed.

\section{RESULT}

In Figure 7 shows the plot of BER versus effective power received for haze conditions based on an FSO system. The pattern of the graph showed a linear decline of BER values for all designs when the received powers are increased. It occurred as the number of bits altered by interference is increased when the power involved is higher. From the graph it can be seen that, Design 3 showed a promising choice for the system as the BER value is at the minimum value which is $10^{-127}$ when the power received is $-26 \mathrm{dBm}$ compared to other designs. The minimum value of BER achieved by Design 2 and Design 1 are $10^{-60}$ and $10^{-34}$ when the received power is $-26 \mathrm{dBm}$ respectively. Based on the result, Design 3 is the most capable design to transmit signals at high performance in haze condition. 


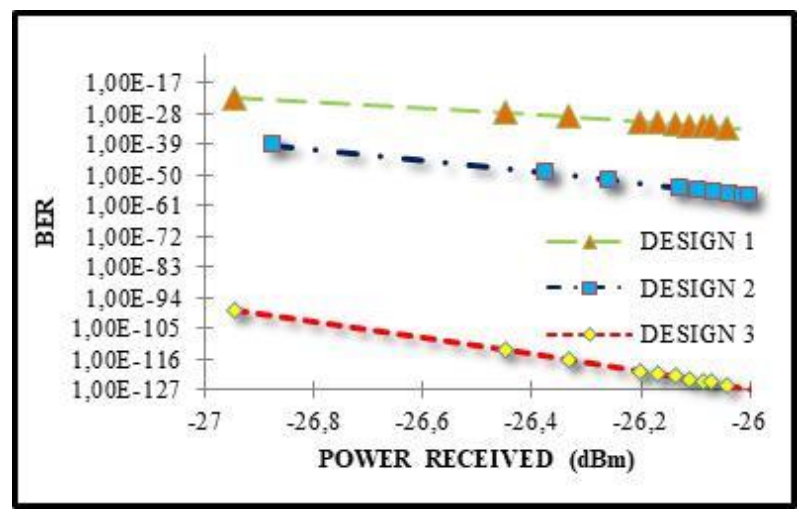

Figure 7. Performance of BER versus power received with different

Figure 8 shows the graph of Q Factor versus the diameter aperture of FSO system in haze condition. The ranges of diameter aperture used in this investigation are $20 \mathrm{~cm}$ until $40 \mathrm{~cm}$. At a diameter aperture of 40 $\mathrm{cm}$, the maximum Q Factor achieved for Design 1, Design 2, and Design 3 are 11.8, 15.8, and 23.6. This high value of Q Factor corresponds to their low values of BER. It can be seen that the Q Factor increased when the diameter aperture increased and thus, the better the performance of the system. This revealed that enlarged aperture is better for the FSO system as the efficiency is improved. So, Design 3 is the best as it is able to minimize the signal attenuation in haze condition efficiently and thus greatly improved the performance of the system.

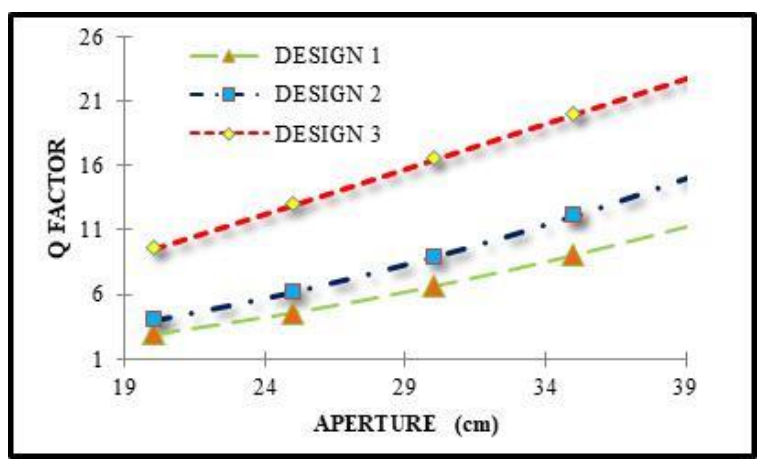

Figure 8. Performance of Q Factor versus aperture diameter with different design

Based on the results obtained from the simulation, Table 2 compiled the minimum value of BER and Q factor achieved by Design 1, Design 2 and Design 3 in haze condition.

Table 2. The minimum Value of Performance Parameter Achieved

\begin{tabular}{lccc}
\hline & Design 1 & Design 2 & Design 3 \\
\hline BER vs Power Received & $10^{-127}$ & $10^{-60}$ & $10^{-34}$ \\
Q factor vs Aperture & 11.8 & 15.8 & 23.6 \\
\hline
\end{tabular}

\section{CONCLUSION}

Haze effects shown to heavily impact the FSO signal in this research as it causes high atmospheric loss $(\mathrm{dB} / \mathrm{km})$. This research emphasized on the design of the FSO system and the evaluation based on the result obtained from the simulation under weather conditions. Despite the high attenuation on the transmitted signal, Design 3 is able to greatly minimize the signal loss as it has achieved the minimum BER which is $10^{-}$ ${ }^{127}$ when the power received is $-26 \mathrm{dBm}$. The $\mathrm{Q}$ factor of Design 3 is 23.6 when the aperture diameter is 40 $\mathrm{cm}$, is also the highest. It can be concluded that Design 3 is the most suitable design to be used in haze condition as it has the criteria required to operate in low visibility. 


\section{ACKNOWLEDGEMENTS}

The author would like to acknowledge the support from the Fundamental Research Grant Scheme (FRGS) under a grant number of FRGS/1/2015/ICT03/UNIMAP/02/2 from the Ministry of Education Malaysia.

\section{REFERENCES}

[1] Majumdar, A. K. (2014). Advanced Free Space Optics (FSO): A Systems Approach (Vol. 186). Springer.

[2] Henniger, H., \& Wilfert, O. (2010). An Introduction to Free-space Optical communication, Radioengineering 19(2).

[3] Reddy, E. M., \& Therese, A. B. (2017, March). Analysis of atmospheric effects on free space optical communication. In Nextgen Electronic Technologies: Silicon to Software (ICNETS2), 2017 International Conference on (pp. 338-343). IEEE.

[4] Grobe, L., Paraskevopoulos, A., Hilt, J., Schulz, D., Lassak, F., Hartlieb, F., \& Langer, K. D. (2013). High-speed visible light communication systems. IEEE communications magazine, 51(12), 60-66.

[5] Bellalta, B. (2016). IEEE 802.11 ax: High-efficiency WLANs. IEEE Wireless Communications, 23(1), 38-46.

[6] Khalighi, M. A., \& Uysal, M. (2014). Survey on free space optical communication: A communication theory perspective. IEEE Communications Surveys \& Tutorials, 16(4), 2231-2258.

[7] Tashiro, Y., Suito, Y., Shimada, Y., Izumi, K., Tsujimura, T., \& Yoshida, K. (2017, February). Transmission quality of bilateral free space optics system. In Mechatronics (ICM), 2017 IEEE International Conference on (pp. 220-225). IEEE.

[8] Shimada, Y., Tashiro, Y., Izumi, K., Yoshida, K., \& Tsujimura, T. (2016). Initial alignment method for free space optics laser beam. Japanese Journal of Applied Physics, 55(8S3), 08RB08.

[9] Singh, H., \& Singh, G. (2017). Performance Analysis of MIMO FSO Link Employing Different Modulation Techniques.

[10] Verma, N. K., \& Narayan, H. (2017). Analysis of Free-space Optical system under DifferentAtmospheric Channel.

[11] Anis, A. A., Rahman, A. K., Rashidi, C. B. M., \& Aljunid, S. A. (2016, August). Link budget analysis for free space optical (FSO) communication under haze condition with adverse wavelength. In Electronic Design (ICED), 20163 rd International Conference on (pp. 354-357). IEEE.

[12] Esmail, M. A., Fathallah, H., \& Alouini, M. S. (2016). An experimental study of FSO link performance in desert environment. IEEE Communications Letters, 20(9), 1888-1891.

[13] Kaur, P., Jain, V. K., \& Kar, S. (2014). Performance analysis of FSO array receivers in presence of atmospheric turbulence. IEEE Photon. Technol. Lett, 26(12), 1165-1168.

[14] Uysal, M., Capsoni, C., Ghassemlooy, Z., Boucouvalas, A., \& Udvary, E. (Eds.). (2016). Optical wireless communications: an emerging technology. Springer.

[15] Prakash, G., \& Nigam, R. (2017, February). Effect of tropical climate on the propagation characteristics of terrestrial FSO links: a case study. In Free-Space Laser Communication and Atmospheric Propagation XXIX (Vol. 10096, p. 100961H). International Society for Optics and Photonics.

[16] Malik, A., \& Singh, P. (2015). Comparative analysis of point to point FSO system under clear and haze weather conditions. Wireless personal communications, 80(2), 483-492.

[17] Naimullah, B. S. S., Hitam, S., Shah, N. S. M., Othman, M., Anas, S. B. A., \& Abdullah, M. K. (2007, May). Analysis of the effect of haze on free space optical communication in the malaysian environment. In Telecommunications and Malaysia International Conference on Communications, 2007. ICT-MICC 2007. IEEE International Conference on (pp. 391-394). IEEE.

[18] Kaur, H., \& Sarangal, H. (2015). „Impact of Various Weather Conditions on Free Space Optics using 4X4 Transmitter/Receiver Combination Integrated with Different Ways of Amplification". International Journal of Advanced Research in Computer and Communication Engineering, 4(3), 388-393.

[19] Shahiduzzaman, K. M., Hassan, M., Karmaker, B. K., \& Biswas, L. K. Scattering Effect on Terrestrial Free Space Optical Signal in Tropical Weather Condition.

[20] Naimullah, B. S. S., Hitam, S., Shah, N. S. M., Othman, M., Anas, S. B. A., \& Abdullah, M. K. (2007, May). Analysis of the effect of haze on free space optical communication in the malaysian environment. In Telecommunications and Malaysia International Conference on Communications, 2007. ICT-MICC 2007. IEEE International Conference on (pp. 391-394). IEEE.

[21] Anguita, J. A., Neifeld, M. A., \& Vasic, B. V. (2006, September). Multi-beam space-time coded systems for optical atmospheric channels. In Free-Space Laser Communications VI (Vol. 6304, p. 63041B). International Society for Optics and Photonics.

[22] Anguita, J. A., Neifeld, M. A., \& Vasic, B. V. (2006, January). Multi-beam free-space optical link using space-time coding. In Waveform Diversity \& Design Conference, 2006 International (pp. 1-4). IEEE.

[23] Trung, H. D., Ai, D. H., \& Pham, A. T. (2015). Average Channel Capacity of Free-Space Optical Mimo Systems over Atmospheric Turbulence Channels. ASEAN Engineering Journal, 5(2), 57-66.

[24] Rashidi, C.B., Aljunid, S.A., Ghani, F., Anuar, M.S., \& Fadhil, H.A. (2012). Code length optimization using Flexible Cross Correlation (FCC) code in OCDMA networks. 2012 IEEE 3rd International Conference on Photonics, 355-359. 


\section{BIOGRAPHIES OF AUTHORS}

Anis Afina Binti Azman (A.A.Anis) received her M. Sc. in Communication Engineering from
Universiti Malaysia Perlis in 2018 and did her Bachelor in Microelectronic Engineering in 2015
from the same university. Currently her field of interest is the 2D EDW FCC in communication
link, a field in which she is pursuing her PhD since April 2018. She has successfully published 8
articles in peer-reviewed International conferences.

